\title{
Duration of chronic active hepatitis and the development of cirrhosis
}

\author{
A VEGNENTE, V F LARCHER, A P MOWAT, B PORTMANN, AND R WILLIAMS
}

Department of Child Health and the Liver Unit, King's College Hospital Medical School, London

SUMMARY Chronic hepatitis implies that clinical and biochemical features of hepatitis have been present for at least 6 months; but irreversible liver damage may occur with subclinical disease suggesting that pathological features should also define chronicity. We examined 28 children with hepatitis B negative chronic active hepatitis to determine whether the severity of abnormal biochemical tests of liver function, raised serum immunoglobulin concentrations, and positive serum autoantibodies, which are characteristic features in immunosuppressant responsive disease, varied with the duration of symptoms. The pattern of abnormality in these patients was similar whether the disease had been present for less than three months, from three to 6 months, or for more than 6 months, and apart from lack of hyperbilirubinaemia was similar in patients presenting with complications of cirrhosis without previous symptoms of liver disease.

Two children died of liver disease. The remainder showed a clinical, biochemical, and immunological response to prednisolone or azathioprine, or both. These drugs have now been withdrawn in 8 patients without relapse, and disease activity is completely suppressed in 13 . Unfortunately, 15 survivors have definite cirrhosis and a further five have possible cirrhosis. Eight of 10 survivors with symptoms of more than 6 months duration before treatment have cirrhosis compared with two of 12 with symptoms of less than 6 months. It is suggested that consideration of this diagnosis at onset of symptoms and immediate immunosuppressant treatment after appropriate confirmatory investigations may reduce the incidence of cirrhosis in hepatitis $B$ negative chronic active hepatitis in children.

Immunosuppressive treatment has been shown to reduce morbidity and prolong survival in prospective, controlled, clinical trials in adults with chronic active hepatitis. ${ }^{1-3}$ No controlled studies have been reported in children but observations in over 200 suggest a similar response to treatment. ${ }^{4-6}$ The clinical, biochemical, and immunological features of chronic active hepatitis are well established. ${ }^{7}$ Symptoms and signs of hepatitis are associated with biochemical evidence of liver damage such as raised serum transaminases, high serum immunoglobulin concentrations, and positive non-organ specific autoantibody tests; liver biopsy appearances are those of chronic, aggressive hepatitis with or without cirrhosis. There is no evidence of hepatitis B infection or metabolic causes of liver disease such as Wilson's disease. Just how long liver disease must be evident before it is considered chronic is controversial-the interval ranges from less than 10 weeks ${ }^{3}$ to more than 12 months, ${ }^{8}$ but the concensus view is 6 months. $^{7910}$ This concern with the duration of hepatitis before treatment may be inappropriate and contribute to treatment failures in both children and adults since patients may have well established cirrhosis when they first become symptomatic, having previously had a sub-clinical hepatitis. ${ }^{11}$ Over one third of 156 children with chronic active hepatitis who had been symptomatic for more than 6 months were dead at the time of reporting. ${ }^{4}$ One third of adult survivors developed cirrhosis. $^{12}$ In contrast, all 26 children in whom treatment began at a mean interval of less than 6 months from onset of symptoms achieved clinical, biochemical, and histological remission without morbidity or mortality. ${ }^{5}$

We have reviewed retrospectively 28 children with chronic active hepatitis to determine whether diagnostic features became more distinctive with increased duration of apparent disease and to assess whether the severity of liver damage, both at 
diagnosis and at most recent follow up, could be related to the duration of symptoms before treatment.

\section{Patients and methods}

Twenty eight children ( 20 girls, 8 boys) mean age $7 \cdot 7$ years, (range 3 to 13 years) seen between 1971 and 1979 had clinical, biochemical, and immunological features of chronic active hepatitis. Percutaneous liver biopsies showed features of chronic aggressive hepatitis in 27 children. Twenty two underwent liver biopsy before treatment but biopsy was delayed in five until the prothrombin time was reduced by immunosuppressant treatment. In one patient who had a small liver, persistent ascites, severe portal hypertension, and prolonged prothrombin time, no liver biopsy was performed. All biopsies were examined by one observer (BP) and histological features were recorded semiquantitatively. ${ }^{13}$ When the hepatic architecture was disturbed but no nodule formation was seen, the biopsy was interpreted as possible cirrhosis.

Serum immunoglobulin concentrations were measured by laser nephelometry using standard antisera and results were expressed in $\mathrm{g} / \mathrm{l}$. Tissue autoantibodies were detected using rat liver, kidney, and stomach substrate. ${ }^{14} \mathrm{~A}$ reaction at the serum dilution of 1:10 was regarded as positive for antinuclear antibody, antimitochondrial antibody, liver/kidney microsomal antibodies, and gastric parietal cell antibodies, while a titre of 1:80 was required for smooth muscle antibodies. ${ }^{15}$

Hepatitis B virus infection was excluded by radioimmunoassay for hepatitis $B$ surface antigen, hepatitis B core antibody and hepatitis B surface antibody. (Abbot Laboratories, USA). Alpha ${ }_{1}$ anti-

Table 1 Presenting features in 28 children with chronic active hepatitis

\begin{tabular}{|c|c|c|c|c|c|}
\hline & \multicolumn{4}{|c|}{ Groups } & \multirow[b]{2}{*}{ Total } \\
\hline & $\begin{array}{l}I \\
(n=6)\end{array}$ & $\begin{array}{l}I I \\
(n=7)\end{array}$ & $\begin{array}{l}I I I \\
(n=11)\end{array}$ & $\begin{array}{l}I V \\
(n=4)\end{array}$ & \\
\hline Jaundice & 6 & 7 & 11 & 0 & 24 \\
\hline Anorexia & 4 & 6 & 7 & 0 & 17 \\
\hline Fever & 3 & 1 & 2 & 0 & 6 \\
\hline Lethargy & 1 & 2 & 0 & 1 & 4 \\
\hline Hepatomegaly & 4 & 6 & 11 & 4 & 25 \\
\hline Splenomegaly & 5 & 4 & 9 & 4 & 22 \\
\hline \multicolumn{6}{|l|}{ Abdominal } \\
\hline distension & 2 & 1 & 6 & 3 & 12 \\
\hline Ascites & 1 & 1 & 2 & 0 & 4 \\
\hline Spider naevi & 1 & 2 & 6 & 1 & 10 \\
\hline Vitiligo & 1 & 0 & 1 & 0 & 2 \\
\hline Striae & 1 & 0 & 0 & 0 & 1 \\
\hline \multicolumn{6}{|l|}{ Gastro-intestinal } \\
\hline bleeding & 1 & 2 & 0 & 2 & 5 \\
\hline
\end{tabular}

trypsin deficiency and Wilson's disease were excluded by appropriate investigations.

The 28 patients were divided into four groups according to the interval between the present onset of jaundice and diagnosis: Group I (6 patients) duration less than three months; group II (7 patients) duration three to 6 months; group III (11 patients) duration more than 6 months; and group IV four patients who presented without jaundice.

Clinical features at diagnosis. In 24 patients the disease started acutely with clinical features indistinguishable from acute hepatitis. Eleven of these children had had a previous episode of jaundice three months to three years before and five had had two such episodes. In four patients liver disease developed insidiously without jaundice; two presented with lethargy, weight loss, abdominal distension, and hepatosplenomegaly and two with gastrointestinal bleeding.

The main clinical features on presentation were similar in all four groups apart from the absence of jaundice, fever, and anorexia in group IV (Table 1). Splenomegaly and spider naevi were more common in the patients with a longer duration of symptoms. Two had ulcerative colitis which in one child (group IV) anteceded the jaundice by 18 months, while in the other (group II), jaundice preceded the ulcerative colitis by five months. One boy of Nigerian ancestry had haemoglobin SC disease. Two girls, cousins living in close contact, developed symptoms within 12 months of one another.

Biochemical test of liver function. Serum concentrations of bilirubin, aspartate aminotransferase (AST), albumin, and prothrombin time were similar in all groups apart from the the low bilirubin concentration in group IV (Fig. 1 (a), (b), (c), and (d)).

Serum immunoglobulins and non-organ specific autoantibodies

The total gammaglobulin concentration was raised in all patients (Fig. 2). Serum immunoglobulins IgG, $\operatorname{IgA}$, and $\operatorname{IgM}$ were measured at the time of diagnosis in all patients, except one in group II and one in group III. The IgG was raised in 24 children, but was normal in one child in group II who had a raised IgM and one child in group III who had high IgM and IgA. Four patients had raised concentrations of all three immunoglobulin subclasses. Four had raised IgG and IgM and one had raised IgG and IgA. The serum immunoglobulin concentrations and distribution of raised subclass values did not differ in the four groups. Non-organ specific autoantibodies, present in all children (Table 2), were evenly distributed in the four groups. 

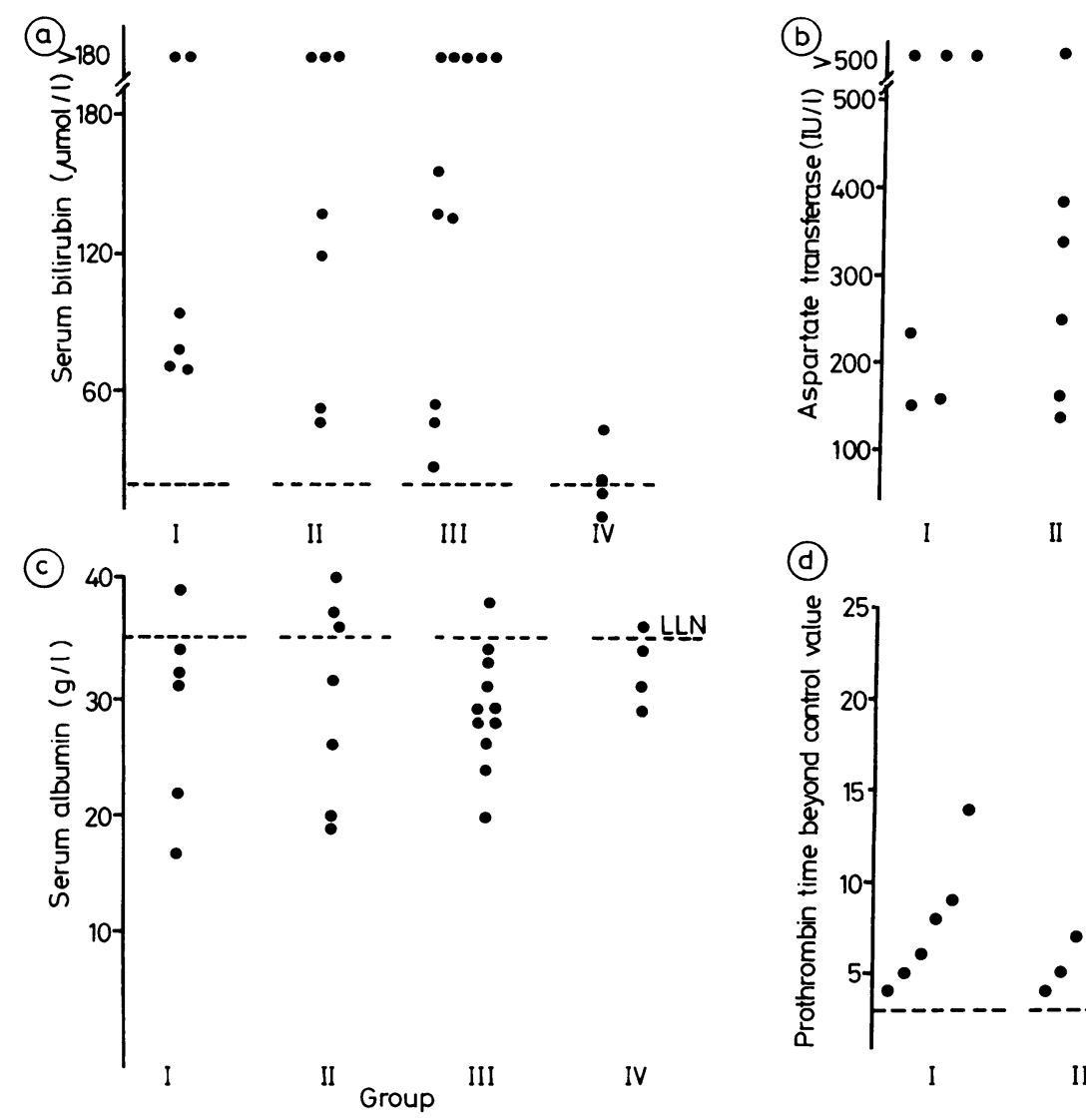

(d)
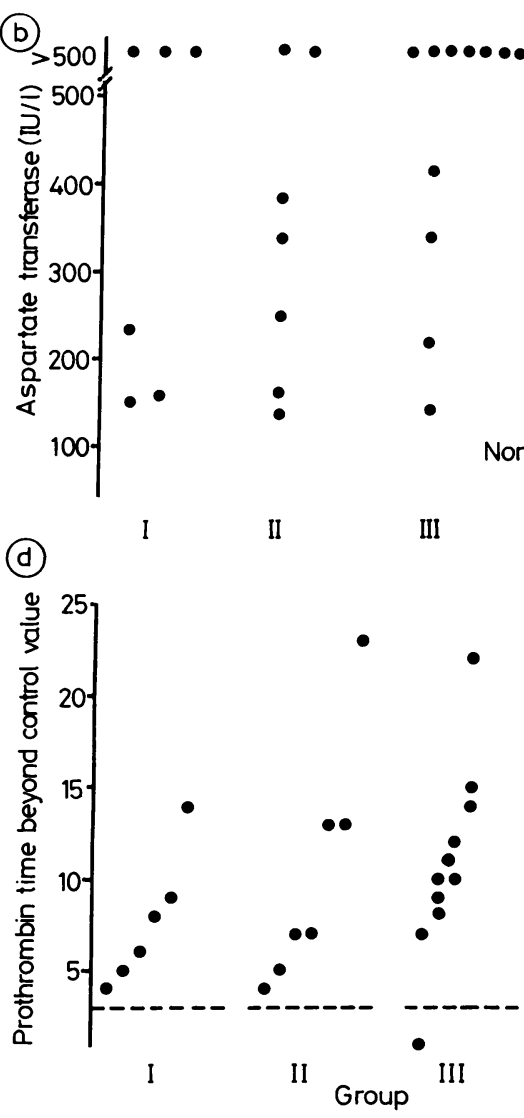

IV

Fig. 1 Biochemical features at diagnosis according to duration of symptoms in 28 children with chronic active hepatitis.

Dotted lines indicate upper or lower limits of normal.

Histological assessment of severity of liver damage Definite cirrhosis was present in 11 patients, a further 13 had possible cirrhosis, and in only three was cirrhosis excluded. In the patients presenting with jaundice the frequency of cirrhosis increased with duration of symptoms (Fig. 3).

\section{Treatment and follow up}

All patients received immunosuppressants with the aim of controlling symptoms and reducing the AST values to within twice the upper limit of normal without appreciable side effects. Prednisolone alone was given to 25 patients at an initial dose of 2 $\mathrm{mg} / \mathrm{kg} / 24$ hours and was gradually reduced over 12 weeks to a dose which did not cause serious cushingoid side effects, usually around $0.25 \mathrm{mg} / \mathrm{kg} /$ 24 hours. In patients in whom satisfactory reduction of AST could not be achieved with prednisolone

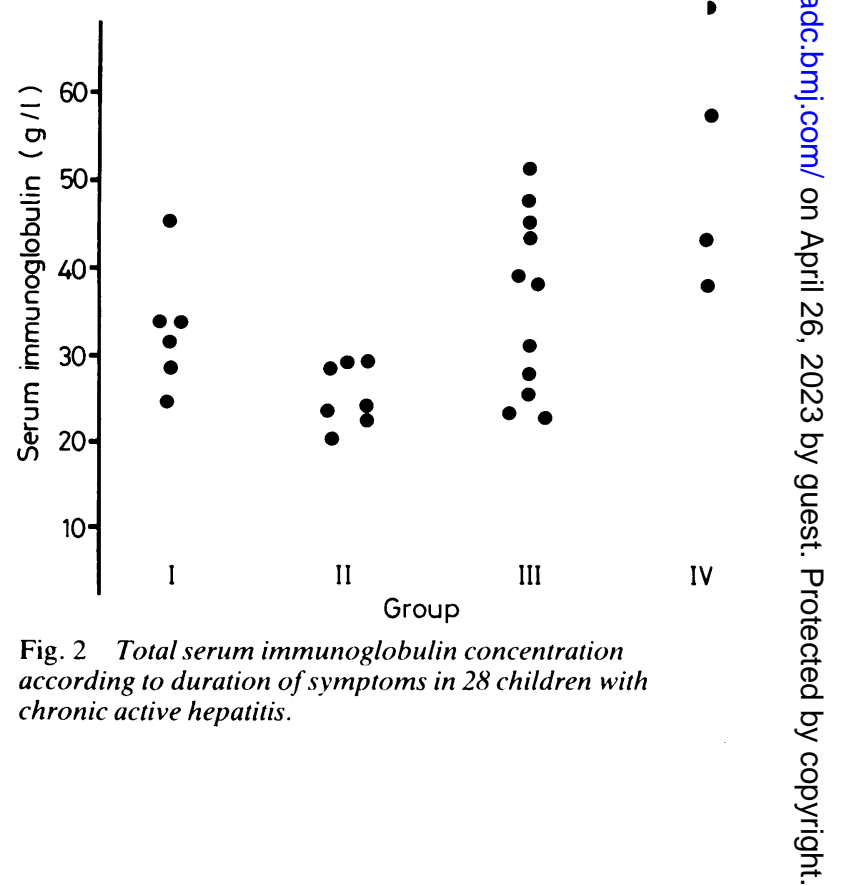


Table 2 Non-organ specific autoantibodies at diagnosis in 28 children with chronic active hepatitis

\begin{tabular}{|c|c|c|c|c|c|c|}
\hline \multirow{2}{*}{$\begin{array}{l}\text { Autoantibody } \\
\text { class }\end{array}$} & \multirow{2}{*}{$\begin{array}{l}\text { No } \\
\text { tested }\end{array}$} & \multirow{2}{*}{$\begin{array}{l}\text { No } \\
\text { positive }\end{array}$} & \multicolumn{4}{|c|}{ Group } \\
\hline & & & $I$ & 11 & III & IV \\
\hline Antinuclear & 28 & 6 & 3 & - & 2 & 1 \\
\hline Smooth muscle & 28 & 8 & - & 2 & 5 & 2 \\
\hline $\begin{array}{l}\text { Antinuclear and } \\
\text { smooth muscle }\end{array}$ & 28 & 5 & 2 & 1 & 1 & 1 \\
\hline $\begin{array}{l}\text { Liver/kidney } \\
\text { microsome }\end{array}$ & 14 & 6 & 1 & 3 & 3 & - \\
\hline Antimitochondrial & 28 & 1 & - & 1 & - & - \\
\hline
\end{tabular}

alone, azathioprine at a dose of $1 \mathrm{mg} / \mathrm{kg} / 24$ hours was given except for those whose leucocyte count was less than $4 \times 10^{9} / \mathrm{l}$ who received $0.25 \mathrm{mg} / \mathrm{kg} / 24$ hours. Two patients were treated throughout with prednisolone and azathioprine and one received azathioprine alone as part of a controlled trial.

Patients were assessed at regular intervals and drug doses modified by monitoring the AST concentrations and the white blood counts. When the AST had been normal for at least one year a liver biopsy was performed and if all features of chronic aggressive hepatitis had resolved treatment was gradually stopped over a three month period. Clinical and laboratory assessment continued at intervals of one to three months.

Effect of treatment. One 7 year old girl (group I) who died within one week of starting prednisolone had had symptoms of hepatitis for only three weeks, with jaundice for only 10 days, although she had previously had an attack of apparent hepatitis 18 months before. Liver function tests did not improve in the 10 year old boy treated with azathioprine alone. It was suspected that he was not taking the drug and he was lost to follow up after one year. At
19 years of age he developed hepatocellular carcinoma with cirrhosis and died 6 months later.

In the remaining 26 patients there was a gradual clinical improvement but in 18 the AST value did not fall satisfactorily until azathioprine was included in the treatment. These 18 children comprised two from group I, five from group II, 8 from group III, and three children from group IV. The AST value returned to the normal range in 8 of 22 patients tested after four months of treatment, 10 of 24 tested at 12 months, 14 of 21 tested at 24 months, and 21 of 26 tested at most recent follow up. Serum immunoglobulins returned to normal in all patients who achieved a satisfactory fall in the AST value. Tisse autoantibodies were still detected in 8 of 17 children tested after four months of treatment and in 8 of 26 at most recent follow up. In two patients high titres of autoantibody persisted more than two years after stopping treatment.

Eight patients, three from group I, two from group II, two from group III, and one from group IV have stopped treatment after taking immunosuppressants for a mean duration of 45 months (Table 3). All have remained free of clinical, biochemical, immunological, or pathological evidence of relapse for periods ranging from 7 months to 84 months (mean 38 months). Three were treated with steroids alone. Three have possible cirrhosis, one definite cirrhosis. Eighteen patients still require treatment. Thirteen are well controlled clinically and biochemically but relapse biochemically when the immunosuppressant dose is reduced below a critical value. These thirteen have been treated for periods ranging from 12 to 96 months (mean 35 months). Three patients receiving both steroids and azathioprine have persistently raised transaminases, two having intermittent jaundice. A further two patients (one in group I and one in group IV) have satisfactory

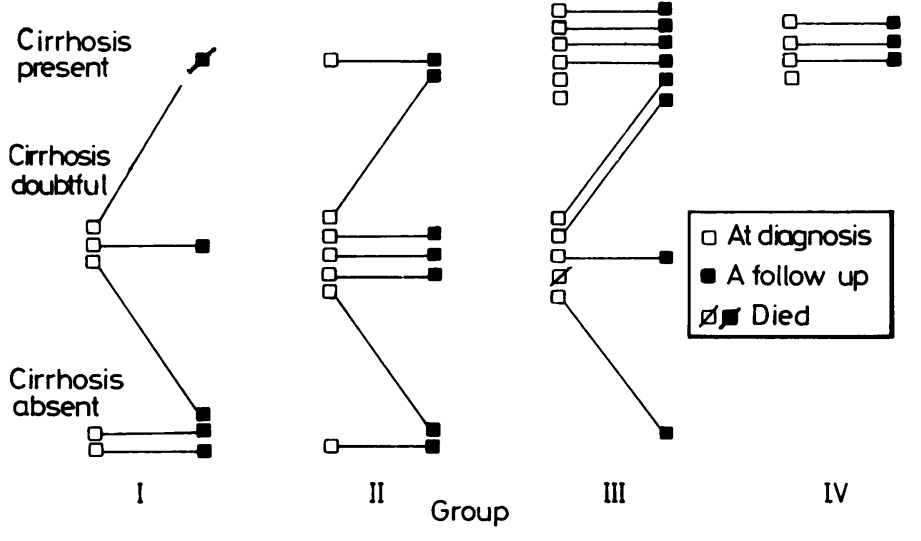

Fig. 3 Liver histology on percutaneous liver biopsy at diagnosis and at latest follow up according to duration of symptoms in 28 children with chronic active hepatits. 
Table 3 Treatment status of 26 surviving patients

\begin{tabular}{|c|c|c|c|}
\hline \multirow[t]{2}{*}{ Group } & \multirow{2}{*}{$\begin{array}{l}\text { Treatment } \\
\text { stopped }\end{array}$} & \multicolumn{2}{|l|}{ On treatment } \\
\hline & & Well controlled & Poorly conrolled \\
\hline I $(n=6)$ & 3 & 1 & 1 \\
\hline II $(n=7)$ & 2 & 4 & 1 \\
\hline III $(n=11)$ & 2 & 7 & 1 \\
\hline IV $(n=4)$ & 1 & 1 & 2 \\
\hline
\end{tabular}

biochemical control but have decompensated cirrhosis with ascites and have had one or more episodes of spontaneous bacterial peritonitis. Follow up liver biopsies have been performed in 23 patients. Cirrhosis was present in all three biopsies from group IV patients, in five of 7 from group III, in two of $\mathbf{6}$ from group II, and in none from group I (Fig. 3).

Side effects of treatment. Cushingoid features developed in the first two months of prednisolone treatment in nearly every child, but subsided when the dose was reduced. Three patients developed peptic ulceration, three had back pain attributed to osteoporosis, and two showed personality changes on a prednisolone dosage of greater than 0.5 $\mathrm{mg} / \mathrm{kg} / 24$ hours. One patient receiving both prednisolone and azathioprine developed a chronic pancreatitis which settled spontaneously after five months. Four with cirrhosis and continuing biochemical abnormality have appreciable growth retardation.

\section{Discussion}

These observations provide further evidence that hepatitis B negative chronic active hepatitis in childhood may be controlled with prednisolone and azathioprine; 26 of 28 patients responded clinically, biochemically, and pathologically. One patient died within one week of diagnosis. Azathioprine, the sole drug given in 1971 to the other patient who died, is now recognised to be inferior to prednisolone as initial treatment. ${ }^{2}$

Four patients presented with cirrhosis or its complications, having had no previous clinical features suggestive of hepatitis. Thirteen of the 24 who presented with jaundice had had features for less than 6 months. These 17 patients would have been denied treatment if duration of symptoms had been an essential criterion for diagnosis. Apart from the absence of hyperbilirubinaemia in the four patients who presented with insidious cirrhosis, the range of clinical, biochemical, and immunological abnormali- ties on which a presumptive diagnosis is based did not vary with the duration of obvious disease. Unfortunately 15 of the survivors have definite cirrhosis (14 confirmed histologically) and a further five have distorted hepatic architecture and possible cirrhosis. The severity of liver disease, both in the initial biopsy and more importantly, in biopsies taken after treatment, seems to be greater in those with the the longest duration of symptoms before treatment. Eight of 10 survivors of patients with symptoms of more than 6 months duration have cirrhosis, compared with only two of 12 with symptoms of less than 6 months.

In other series ${ }^{4} 61617$ in which a duration of hepatitis of more than 6 months has been a criterion for diagnosis, even greater mortality and similar morbidity have been reported. In contrast all 26 patients reported by Arasu ${ }^{5}$ for whom diagnosis was made on accepted clinical, immunological, and pathological criteria but with a duration of symptoms that ranged from 6 weeks to 19 months (mean 5 months) responded clinically, biochemically, and histologically to treatment and there were no deaths. Only two were thought to have had cirrhosis at diagnosis but unfortunately the incidence of cirrhosis after treatment was not determined. While it may be arguable that some of these patients might have got better without treatment, the pathological features and immunological abnormalities such as IgG autoantibodies which were present in these patients are exceptional in self limiting hepatitis. ${ }^{18}$

The high incidence of cirrhosis in chronic active hepatitis is not confined to children. ${ }^{19}$ Even with the early institution of the currently most satisfactory treatment regimen of prednisolone and azathioprine, up to $33 \%$ of adult patients may progress to cirrhosis, ${ }^{12}$ and clearly an ideal treatment regimen is still to be developed. ${ }^{11}$ Higher doses of prednisolone, perhaps given on alternate days, have been suggested, ${ }^{11}$ but a controlled clinical trial will be necessary to confirm the efficacy of this.

To what extent the treatment of children should follow guidelines derived from studies in adult patients remains uncertain. A notable difference from adult patients which emerges from this study and that of Arasu is the low frequency of relapse; prolonged withdrawal of therapy was possible in 8 of 28 in this study and 19 of 28 in the study of Arasu. ${ }^{5}$ This is to be compared with the $100 \%$ relapse rate reported by Hegarty et $a l^{20}$ and Czaja et al. ${ }^{21}$

The observations made in this small series of children suggests that the time has now come for a revision of the accepted definition of chronic active hepatitis with a view to earlier diagnosis in the hope that liver damage will be less advanced when immunosuppressive treatment is instituted. All the 
patients in this series began treatment before serum markers for type A hepatitis were available. To what extent the availability of these and the future development of serological markers for non-A, non- $\mathrm{B}$ hepatitis may clarify the early identification of chronic active hepatitis cannot be determined at this time.

We recommend that any child with a hepatitis that has not been shown to be type A or type B hepatitis, should be assessed for possible chronic active hepatitis by serum immunoglobulin and antinuclear factor, and smooth muscle and liver/kidney microsomal autoantibodies determination with percutaneous liver biopsy to show chronic active hepatitis irrespective of the duration of symptoms.

The patient should also be investigated to exclude other treatable chronic hepatobiliary disorders such as Wilson's disease, choledochal cyst, or constrictive pericarditis. If this approach is adopted it could lead to a reduction in the number of patients with chronic active hepatitis who progress to cirrhosis. Further studies will be required to confirm this assertion.

We thank Mrs Pamcla Golding for typing the manuscript.

\section{References}

1 Kirk AP, Jain S, Pocock S, Thomas HC, Sherlock S. Late results of the Royal Free Hospital prospective control trial of prednisolone therapy in hepatitis B surface antigen negative chronic active hepatitis. Gut 1980;21:78-83.

2 Murray-Lyon IM, Stern RB. Williams R. Controlled trial of prednisolone and azathioprine in active chronic hepatitis. Lancet 1973;i:735-7.

3 Soloway RD. Summerskill WHJ, Baggenstoss A. et al. Clinical, biochemical and histological remission of severe chronic active liver discase: a controlled study of treatments and carly prognosis. Gastroenterology 1976;63:820-33.

4 Silverberg M. Chronic liver discase in children. In: Chandra RK. ed. Liver and biliary system in infants and children. Edinburgh, London, New York: Churchill Livingstone, 1979.

5 Arasu TG, Whyllic R. Hatch TF. Fitzgerald JF. Management of chronic aggressive hepatitis in children and adolescents. J Pediatr 1979;95:514-22.

${ }^{6}$ Dubois RS. Silverman A. Slovis TL. Chronic active hepatitis in children. Am J Dig Dis 1972;17:575-82.
7 Diseases of the liver and biliary tract. Standardisation of nomenclature, diagnostic criteria and diagnostic methodology. Washington D.C.: Fogarty International Center Proceedings No. 22, 1976. (DHEW Publication No (NIH) 76-725).

* Alagille D, Gautier M. Hadchouel M. Herouin C. Chronic hepatitis in children. Acta Paediatr Scand 1973;62:566-70.

${ }^{9}$ Boyer JL. Chronic hepatitis: a perspective on classification and determinants of prognosis. Gastroenterology 1976;70:1161-71.

10 Summerskill WHJ. Chronic hepatitis-1975 (editorial). Am J Dig Dis 1975:20:1087-90.

11 Czaja AJ. Current problems in the diagnosis and management of chronic active hepatitis. Mayo Clin Proc 1981;56:311-23.

12 Czaja AJ, Wolff AM. The risk of cirrhosis in steroid treated severe chronic active hepatitis (CALD). Gastroenterology 1979:77:8-15.

13 Jensen DM, McFarlane IG. Portmann BS, Eddleston ALWF, Williams R. Detection of antibodies directed against a liver specific membrane lipoprotein in patients with acute and chronic hepatitis. N Engl J Med 1978:299:1-7.

${ }^{14}$ Roitt IM, Doniach D. Immunofluorescent tests for the detection of autoantibodies. WHO manual of auto-immune serology. Geneva: World Health Organisation, 1979.

15 Doniach D, Roitt IM. Walker JG. Sherlock S. Tissue autoantibodies in primary biliary cirrhosis, active chronic (lupoid) hepatitis, cryptogenic cirrhosis and other liver diseases and their clinical implications. Clin Exp Immunol 1966;1:237-62.

16 Lidman K. Biberfeld G, Sterner G, Norberg R. Chronic active hepatitis in children. A clinical and immunological long-term survey. Acta Paediatr Scand 1977:66:73-9.

17 Buts JP. Van Craynest MP. Pinto MJ. Gosseye S, Maldaque P. De Meyer R. Chronic B and non-B hepatitis in childhood. Review of 25 cases. Acta Paediatr Belg 1980:33:111-7.

18 Tag-Gensen U, Permin H, Hardt F, et al. Circulatory autoantibodies in patients with acute viral hepatitis. Scand J Gastroenterol 1980;15:229-30.

19 Sherlock S. Chronic hepatitis. In: Disease of the liver and biliary system. 6th ed. Oxford: Blackwell Scientific Publications, 1981:291.

20 Hegarty JL. Nouri Aria KT. Portmann BS, Eddleston ALWF, Williams R. Relapse following treatment withdrawal in patients with autoimmune chronic active hepatitis. Hepatology 1983;3:685-9.

${ }^{21}$ Czaja AJ, Ammon HV, Summerskill WHJ. Clinical features and prognosis of severe chronic active liver disease (CALD) after cortico-steroid induced remission. Gastroenterology 1980;78:518-23.

Correspondence to Dr A P Mowat. Department of Child Health, King's College Hospital Medical School. Denmark Hill, London SE5 8RX.

Reccived 5 January 1984 